\title{
La estructuración de la subjetividad popular y el problema de la política
}

\section{The structuring of the popular subjectivity and the politics's problem}

Nicolás Angelcos ${ }^{l}$

\section{Resumen}

El artículo presenta una discusión en torno a la participación política vista desde la experiencia subjetiva que construyen los pobladores de la comuna de Cerro Navia, Chile. La hipótesis desarrollada se relaciona con la construcción de un registro político de la subjetividad popular, no considerado en la discusión respecto al tema, en torno a las dimensiones del reconocimiento y la pobreza. Este registro, expresado de forma individual en los jóvenes, puede ayudar a la comprensión de la distancia entre las orientaciones de la acción y su relación con la política institucional.

Palabras clave: Politica, Subjetivación, Reconocimiento, Pobreza.

\section{Abstract}

The article presents a discussion on the issue of political participation from the point of view of the subjective experience that the inhabitants of shantytowns in the area of Cerro Navia build, Chile. The developed hypothesis is related to the construction of a political record of the popular subjectivity, not considered in the discussion on the subject, about the dimensions of the recognition and poverty. This record, expressed individually in young population, can help the understanding of the distance between the action orientations and its relationship with institutional politics.

Key words: Politics, Subjectivation, Recognition, Poverty.

1 Nicolás Angelcós, Licenciado y sociólogo de la Universidad de Chile. Master en Ciencias Sociales, mención Sociología en l' École des Hautes Études en Sciences Sociales de Paris, Francia. Actualmente, doctorante adjunto al Centro de Análisis e Intervención Sociológica (CADIS) de la misma escuela, bajo la dirección del sociólogo Michel Wieviorka. nicolas.angelcos@ehess.fr 


\section{Introducción}

Uno de los problemas de la democracia chilena actual, unido al hecho de que convive con amplios márgenes de desigualdad, es que tiene una muy baja tasa de participación política. Despolitización, apoliticismo, apatía política, son todos términos que buscan nombrar un mismo fenómeno, el distanciamiento de los chilenos y chilenas de la política institucional y, como contrapartida, la debilidad de organizaciones políticas autónomas.

Si bien la demanda de participación política es transversal, son los sectores populares los más afectados por este proceso de despolitización de la sociedad chilena. En primer lugar, porque frente a una distribución tan desigual del poder y la riqueza a nivel nacional, son incapaces de generar una organización fuerte y estable que equilibre las relaciones de poder ante una eventual negociación. En segundo lugar, porque esa debilidad organizacional les impide construir una alternativa política de carácter más incluyente, donde democracia política y social se articulen de forma más eficiente. Finalmente, porque la crisis de representación, a la cual se alude regularmente, impacta de forma diferenciada, siendo los sectores populares los grandes ausentes del panorama político.

Para entender este "déficit" de la participación popular en la política institucional y la ausencia de alternativas al modelo neoliberal existen, de modo esquemático, dos posibles caminos interpretativos. El primero consiste en identificar las reformas estructurales que están a la base de los procesos actuales. En relación a los sectores populares, las dimensiones más estudiadas son: la reducción de la protección social ligada a la transformación del Estado (Castel, 2009); la precariedad y flexibilidad del mercado laboral (Figueroa, 2002); los obstáculos impuestos a la acción sindical (Campero \& Cortázar, 1988); la ya mencionada crisis de representación política; la deficiente modernización capitalista incapaz de integrar a los distintos grupos al mundo del trabajo (Baño \& Faletto, 1999); el paso de una sociedad industrial hacia una sociedad postindustrial (Garretón, 2000); y la rigidez de los mecanismos institucionales constitutivos de la democracia formal (Faletto, 1993). Si bien todas estas reformas y deficien- 
cias del "modelo chileno" explican en gran parte la atomización social, a mi juicio, son incapaces de explicar en qué medida los diferentes actores son interpelados o no por la política.

La segunda alternativa consiste en comprender la subjetividad de los actores populares, lo que implica entender cómo éstos experiencian sus propias vidas y en qué medida la política es un horizonte de sus acciones. En este marco, parece improcedente hablar de "despolitización" de los sectores populares si no comprendemos primero cuál es la significación que un sujeto le atribuye a ese término, a partir de la experiencia de la pobreza y la exclusión social (Castel, 2009; Paugam, 2002).

Inscribiéndose en esta segunda perspectiva, el siguiente artículo intenta comprender la distancia entre la política institucional y los sectores populares a partir de la interpretación de los procesos de subjetivación que estos últimos experimentan.

A continuación, definiremos el perfil teórico de nuestra línea de argumentación.

La pregunta por la subjetividad es inmanente a la Modernidad. Ante los distintos procesos de cambios sociales, políticos y culturales, los pensadores ilustrados se preguntaron por el lugar específico en donde estas transformaciones encontrarían una síntesis. El filósofo más influyente, desde este punto de vista, es Kant. Para él, el sujeto trascendental y la conciencia, como lugar del pensamiento a priori, son los únicos capaces de dar forma y significar la multiplicidad de hechos empíricos. El sujeto, como tal, no aparece inmerso en el devenir histórico pues las categorías con que opera son trascendentales (Hopenhayn, 1997).

Las concepciones contemporáneas de la subjetividad rechazan esta trascendentalidad del sujeto, pues parece inconcebible la idea de un ente más allá de las relaciones sociales. Distintos "descubrimientos" fundamentan esta idea, entre los que destacan la "muerte de Dios" anunciada por Nietzsche, es decir, la inexistencia de un significado único que sea capaz de sintetizar la multiplicidad; la pregunta por el inconsciente elaborada por Freud, donde existe un espacio opaco poblado de instintos y placeres que escapan a la reflexión consciente; y el dasein heideggeriano que plantea la relación intrínseca entre el sujeto y el devenir histórico. 
Adorno y Horkheimer (2004), recogiendo planteamientos provenientes de la crítica kantiana, la filosofía de Nietzsche y Hegel, el materialismo marxista y la teoría de la racionalización de Weber, construyen una potente crítica en torno a las consecuencias y potencialidades de la razón, donde la "Dialéctica de la Ilustración" constituye el nodo conflictivo.

La dialéctica de la ilustración implica una relación conflictiva entre racionalidad y mito. Mientras la razón se erige como el único medio capaz de dominar la naturaleza y, con ello, liberar al hombre de la eterna repetición que conlleva el mito, su devenir en racionalidad instrumental tiene como principal consecuencia la reificación de la naturaleza, cosificando la relación dialéctica entre el sujeto y ésta. Con ello, la razón ocupa el lugar del mito en la comprensión del mundo, sin implicar una superación sino más bien un sacrificio (Adorno \& Horkheimer, 2004).

El hombre, a la vez que subjetiva la naturaleza, la objetiva, privándola de toda posible significación, sacrificando aquello viviente que el sujeto debiera conservar para constituirse como tal. La institución del sacrificio se convierte en la clave para comprender el estatuto de la subjetividad moderna. El sujeto se sacrifica o sacrifica a otros hombres para restituir una alianza en creciente divorcio con la naturaleza. El sacrificio presenta un doble carácter: por un lado, es una autodonación mágica del individuo al colectivo y, por el otro, es autoconservación. O sea, el sujeto se niega o desaparece para restituir la autoridad del colectivo sobre la naturaleza, al mismo tiempo que esa negación es la base de su conservación.

A partir de la relación entre subjetividad y dominación, nos parece relevante introducir el planteamiento de Foucault. Para este autor, la individualidad moderna puede ser comprendida en torno a una doble problemática: por un lado, en relación al surgimiento de la sociedad disciplinaria y, con ella, la fabricación de "cuerpos dóciles"; y, por otro, como la "inquietud de sí" y los "modos de vida" que se configuran en los límites de lo normalizado. Así, Foucault (2007) nos entrega dos tesis fundamentales: 1) el poder produce subjetividad; 2) la crítica y resistencia no pueden situarse "fuera" del poder sino que se instituyen en sus límites. Esto implica, primero, que el poder no debe identificarse con su expresión 
institucional y, segundo, que la subjetividad, aunque producida, constituye un eterno desafío al poder.

Conjugando conceptos postestructuralistas y marxistas, Laclau y Mouffe (1987) plantean la centralidad del antagonismo en la sociedad. La realidad ontológica que subyace a su producción implica la existencia de conflictos y relaciones antagónicas que el sujeto debe enfrentar. En la construcción de la hegemonía social el individuo adopta una "posición de sujeto", la cual articula los diferentes antagonismos. Así, la identidad del sujeto no estaría definida a priori, sino que sería inmanente a la lucha hegemónica por la significación de la sociedad.

En la misma línea, Rancière (2006) propone la tesis siguiente: los procesos de subjetivación política deben entenderse como una desidentificación respecto a la asignación de roles e identidades propios de un orden policíaco. La política, al contrario, consiste en romper, mediante la igualdad, con las jerarquías y distinciones con que opera el reparto de lo sensible.

Así, podemos definir el carácter político de la subjetividad, en tanto constituye un proceso histórico mediante el cual los individuos y colectividades, imbricados en relaciones de poder antagónicas, luchan por construir un sujeto cuya identidad sea el fruto de una nueva significación.

Esta identidad, a juicio de Rancière, no puede comprenderse fuera de la sociedad, es decir, en la ausencia de otro. Más bien es la igualdad con el otro aquello que cuestiona las jerarquías sociales.

Touraine (1992) interpreta este conflicto entre producción y construcción de identidades a partir de la tesis del desacople entre actor y sistema. El funcionalismo plantea una noción de la sociedad según la cual los valores y normas generales, materializados en instituciones, definen y asignan los roles que los individuos ocupan. Para Touraine, esta concepción cumple la función "ideológica" de ocultar las relaciones sociales que se orientan hacia la producción de la sociedad y que, por tanto, cuestionan esta asignación y la reproducción social.

Touraine desarrolla, primero, la noción de movimiento social y, segundo, el concepto de sujeto. La tesis que subyace a ambas abstracciones dice relación con la incapacidad de las normas de interpelar y realizar 
al conjunto de la sociedad. El sujeto constituye un "deseo de ser actor" (Touraine \& Khosrokhavar, 2000, p. 38), es decir, una aspiración cultural, material y política que no se realiza en las instituciones existentes y que busca transformar la sociedad. Ese deseo aparece, en principio, individualmente, bajo la forma de un sufrimiento, agravio o desgarro de la identidad. Sin embargo, la posibilidad de transformar los valores y significados con los cuales ésta se construye depende de la capacidad de articularse (posición de sujeto) en torno a proyectos colectivos que desafíen las orientaciones culturales hegemónicas.

En esta investigación se intentó recuperar estos sufrimientos individuales y el significado manifiesto o latente que expresaban. Del mismo modo, se articularon dichos sufrimientos en torno a grandes dimensiones que los agrupan, posibilitando desarrollar una crítica, es decir, una evidencia de los límites de la política institucional y su incapacidad para interpelar a las distintas subjetividades que pueblan el medio popular.

Carácter de la investigación y metodología empleada

Este trabajo constituye una síntesis de las principales reflexiones y resultados obtenidos en la memoria que desarrolló el autor del presente artículo para la obtención del grado de "Master en Sciences Sociales, mention sociologie" titulada "Léloignement des pobladores de la politique institutionnelle chilienne" (El distanciamiento de los pobladores de la política institucional chilena).

Cabe recalcar que los datos utilizados (fuentes primarias) pertenecen a la investigación "El juicio ciudadano a las políticas sociales" (Ministerio de Planificación y Cooperación, 2003).

Dicho informe tenía por objetivo la creación de un dispositivo operacional que permitiera conocer el juicio ciudadano, los factores que lo conforman, a partir de la identificación de las políticas sociales que generan un vínculo mayor con el Estado. Para ello, se realizaron 28 grupos de discusión, de los cuales 16 se hicieron en Santiago.

De toda la información recogida, para el desarrollo de este análisis se trabajó sobre los cuatro grupos de discusión realizados en Cerro Navia. 
Esto, por diferentes razones, entre ellas dentro de las comunas que incluía el informe (Cerro Navia, La Florida y la Granja), Cerro Navia es la comuna que presenta mayores niveles de pobreza. Dicho factor, que pudiera parecer arbitrario, será clave tanto en la pretensión teórica como empírica de la investigación.

Los grupos de discusión contaron con la participación de 8 personas en promedio, con marcadas diferencias de edad y género. El elemento que homogeniza la diversidad de personas al interior de los grupos es la condición dirigente o ex dirigente social. Esto es de alta relevancia dado que permite mostrar cómo las personas que "participan políticamente" evalúan, afirman y critican el desarrollo de la política institucional.

El factor generacional presente en los grupos es otro elemento importante, dado que la experiencia de las personas más jóvenes se distancia bastante de las demás, principalmente en la relación indirecta y menos traumática que tienen con la dictadura militar y el movimiento de pobladores de los años ochenta.

Un tercer elemento es la pregunta con la cual se interpeló a los participantes: "Si bien el Estado chileno ha invertido muchos recursos para superar la pobreza, el juicio de los chilenos sobre las políticas públicas es negativo, ¿cuál es su percepción de dicho fenómeno?”. Lo interesante de esta pregunta radica en la movilización que se hace de la pobreza, en tanto prenoción con la cual deben enfrentarse los participantes, al mismo tiempo que establece un nexo entre el Estado y dicha población calificada como "pobre" a través de las políticas públicas.

Esta investigación presenta algunas limitaciones importantes debido a la fuente de datos primarios que utiliza: 1) no se diferencia a las poblaciones estudiadas según su origen histórico, es decir, si constituyen el resultado de una toma de terrenos o es una población SERVIU ${ }^{2}$. Al respecto, las concepciones de la historia chilena, la política y la lucha social eventualmente pueden diferir según ese origen histórico. 2) No se diferencia a los entrevistados según su trayectoria social sino según su

2 Servicio de Vivienda y Urbanización, dependiente del Ministerio de Vivienda. Su misión es construir planes habitacionales para sectores desfavorecidos, teniendo especial cuidado en los factores de integración social. 
desempeño como dirigente. Otros datos sociales (empleo, nivel de pobreza) y culturales (nivel de escolaridad, acceso a bienes de información, etc.) con los que no se cuenta para este análisis podrían ser de relevancia. 3) No se consideran los procesos de degradación social, es decir, de presencia de drogas y delincuencia. Esto podría definir de forma categórica el nivel de temor e incertidumbre en los individuos.

Esta investigación utilizó solamente metodología cualitativa, más allá de la introducción de algunos datos estadísticos a modo de referencia. Desde la perspectiva que se pretende mostrar, los procesos de subjetivación deben ser captados en el marco de la producción discursiva, ya sea individual o colectiva, dado que la experiencia que desarrollan los sujetos pone en juego las categorías sociales con que el análisis estadístico pretende fijar los límites de una población. En ese sentido, no hay exclusión ni marginalidad en sí: es el sujeto que deviene excluido o marginal a partir de una experiencia específica de la pobreza.

Dado que se buscó una estructura más o menos homogénea entre los discursos, el análisis tuvo varias etapas. Una primera etapa consignó la codificación de todas las manifestaciones que expresan una cierta disconformidad, sufrimiento o crítica, independiente de la dimensión referida. A la inversa, también se codificaron aquellas expresiones que muestran una cierta identificación, ya sea con el movimiento histórico de pobladores, con la población misma, con algún proyecto político, con alguna organización social, etc. En una segunda etapa, se articularon los discursos pertenecientes a cada grupo tomado de forma independiente. Esto se hizo para recuperar la unidad de cada discusión y marcar las diferencias generacionales (dada la importancia de la dimensión dictadura como trauma o marca de la sociedad chilena). Luego, en una tercera etapa se agruparon las críticas y afirmaciones respecto a las dimensiones más recurrentes, a saber: 1) pobreza; 2) políticas públicas; 3) política institucional (municipios, Estado, partidos políticos). Estas categorías fueron empíricamente fundadas. Así, se construyeron dos grandes problemas: 1) la estructuración de la subjetividad (el distanciamiento y crítica respecto a los roles con los cuales se sienten interpelados) en torno a dos ejes, también empíricamente fundados: a) la pobreza; b) el reconocimiento (de aquello que parece ser 
negado por las instituciones); y 2) la relación con la política institucional, donde se fusionaron las dimensiones política y políticas públicas, dada la similitud de los argumentos registrados.

El paso inductivo desde el análisis empírico a la construcción de categorías abstractas no tenía por objetivo ser representativo del conjunto de las poblaciones ni de la diversidad de problemas que enfrentan los pobladores. El objetivo fue identificar una estructura subjetiva y mostrar los rendimientos interpretativos que esto tiene para la comprensión del distanciamiento de la política.

Para lograr este objetivo se realizó un análisis crítico del discurso. Este análisis consiste en la identificación del texto, es decir, de la estructura y coherencia del argumento que expresa la intención comunicante del hablante. En un nivel más amplio, se considera al discurso como una práctica inscrita en una práctica social más amplia. Esto implica estimar las ideologías y significaciones que el discurso encierra. Así, se procedió desde una descripción de los textos, donde la dimensión "pobreza" ocupaba un lugar central. En segundo lugar, se interpretó la práctica discursiva como un tipo de subjetivación particular. Finalmente, se buscó explicar el problema del distanciamiento de la política como la incapacidad de la política y los significados asociados a ella de interpelar a los sujetos.

La identificación de lo político a la política institucional

La participación de los chilenos en la política institucional ha sido un tema ampliamente discutido en el campo de las ciencias sociales.

La dimensión central alrededor de la cual se han concentrado dichos estudios es la tasa de inscripción en los registros electorales. Así, para el plebiscito del año 1988, donde se jugaba la actualidad y el futuro de la dictadura, el 90,7\% de los jóvenes participó en las elecciones; sin embargo, dos años más tarde, en las primeras elecciones presidenciales después de diecisiete años, solo el 50\% de los jóvenes en edad de votar hizo efectivo ese derecho.

A partir de este fenómeno, la literatura sociológica ha trabajado principalmente en torno a dos explicaciones: la primera habla de una normalización de las tasas de participación electoral, es decir, la alta 
participación registrada durante el plebiscito se puede explicar por el momento decisivo que implicaba este evento en la historia política chilena. La caída experimentada dos años más tarde no significaría más que la vuelta a las tasas históricas de participación electoral, ya observadas antes del golpe de Estado del año 1973.

La segunda explicación identifica dimensiones mucho más comprensivas del fenómeno, orientando la investigación hacia el comportamiento político de los jóvenes, asumiendo la fuerza identitaria de dicha categoría. Se habla, de esta manera, de una apatía política de los jóvenes, producto de una socialización política llevada a cabo principalmente en el núcleo familiar, así como también de una desconfianza generalizada en torno al régimen. Otras interpretaciones se detienen más bien sobre la importancia en la construcción de redes sociales en el entorno juvenil (clubes deportivos, talleres de rock, preuniversitarios populares, entre otros) conformando una identidad allende la política nacional.

A medida que la década de los noventa avanza, la caída de la participación electoral no cesa de expandirse. Actualmente, 30,7\% del total de los jóvenes en edad de votar están inscritos, al mismo tiempo que el 68,1\% no muestra ningún interés por ejercer dicho derecho (Ruiz, 2008). Estas elocuentes cifras llaman una vez más la atención, tanto de las autoridades políticas como de los investigadores sociales, sobre el comportamiento político de la juventud.

En este contexto, las principales dimensiones que han dominado el espectro de interpretaciones son: las diferencias generacionales y la pobreza.

En relación a la primera, diversos estudios han subrayado la centralidad del distanciamiento entre las experiencias juveniles y las experiencias adultas, marcadas por el trauma de la dictadura. En este sentido, los jóvenes presentarían mayores niveles de apatía política que los adultos (Baño \& Faletto, 1992; Toro, 2005; Madrid, 2005).

El estudio realizado por Sergio Toro (2005), dentro de la misma perspectiva, muestra un análisis más fino. Como marca constitutiva de la participación política, el autor destaca el plebiscito del año 1988. Así, si bien se considera la distancia generacional, la apatía no correspondería solamente al segmento de los jóvenes, sino también a aquellos adultos que no participa- 
ron en dicho proceso, ampliando la magnitud del problema en cuestión.

Pese a las diferencias entre estas investigaciones, todas hablan de la centralidad que ha adquirido la individualización en las trayectorias juveniles. En esta perspectiva, el distanciamiento frente a la política es el producto del aislamiento del individuo en relación a la producción de identidades colectivas (González, Manzi, Cortés, Torres, De Tezanos, Aldunate \& al., 2005). Podría incluir en esta línea los postulados de Norbert Lechner (2002) y el efecto de ellos sobre el Informe de Desarrollo Humano, realizado por el PNUD el mismo año.

Esta distinción del individuo respecto a su comunidad es explicada de dos formas distintas: por una parte, Luis Ruz (2008) muestra cómo los jóvenes "desfavorecidos" son incapaces de realizar su individualidad más allá de los obstáculos que le imponen ciertas determinaciones sociales. Estos individuos, dada la ausencia de soportes sociales necesarios para enfrentar las condiciones de precariedad que los afectan, serían incapaces de afirmar un mínimo de independencia social (Castel, 2009).

Rodrigo Baño (1992) interpreta esta individualización a partir del concepto de apoliticismo, donde el individuo chileno contemporáneo aparece como la expresión de un individuo-masa, incapaz de conducir las orientaciones políticas de la sociedad.

El sujeto es visto, desde esta perspectiva, como un producto de la socialización. La subjetivación es un proceso de interiorización, de parte del individuo, del vínculo político.

La segunda dimensión relevante es la pobreza. Junto al trabajo de Ruiz (2008), Aranda y Cuevas (2008) muestran cómo la juventud, cuando experimenta la pobreza, deviene una realidad dramática que pesa sobre su subjetividad.

Las determinaciones de edad, la relación entre las generaciones o la estratificación social que incide sobre los comportamientos políticos de las personas nos diseñan un cuadro fundamental donde es posible situar el problema, pero poco nos dicen en relación a la experiencia social de aquellos jóvenes o personas pobres.

Ya no se trata de estudiar la relación de unas personas ya constituidas con una política institucional bien definida (municipalidades, partidos políti- 
cos, Estado), sino más bien de detener la mirada sobre los procesos mediante los cuales la subjetividad se construye; qué concepción de lo político se deriva de ello y qué tipo de relaciones se establecen con la política institucional.

La estructuración de la subjetividad popular. Las dimensiones de la pobreza y el reconocimiento. Hacia un desplazamiento de lo "político"

Como se mencionó, la bibliografía chilena se ha referido a la dimensión "pobreza" para comprender la desafección política, en tanto obstáculo estructural para la participación. En la primera etapa del análisis realizado, esta misma dimensión fue muy recurrente. Si bien esto puede ser explicado por la pregunta inicial que orientaba la discusión en los grupos, en relación a las políticas públicas para la superación de la pobreza, parece exagerado subordinar a ésta toda la reconstrucción biográfica y los discursos críticos que los pobladores elaboraron.

Al mismo tiempo, si bien esta dimensión puede parecer particular para interpretar los discursos, Merklen (2009) muestra cómo los barrios populares devinieron, en la mayoría de los países del cono sur, como el centro de las estrategias rotuladas bajo la marca de las luchas contra la pobreza. Estas estrategias marcan un cambio en la orientación no solo de las políticas públicas y la protección social, sino también en la reflexión que adoptan las ciencias sociales, las intervenciones de las Organizaciones no gubernamentales (ONG) y el rol que pasan a ocupar las organizaciones barriales por sobre las estructuras sindicales. Así, el paso de la figura del "trabajador" al "pobre" implica una reconfiguración de lo que Merklen denomina la "politicidad" ("politicité) de los barrios populares.

La hipótesis que se quiere demostrar en esta sección es que la "pobreza”, en tanto categoría con la cual se interpela a los individuos de los barrios pobres, actúa como un "detonador" de subjetividad, ya que es incapaz de comprender la "sociabilidad" que encarna la experiencia popular. En resistencia a la imposición del calificativo "pobre", los pobladores expresan su deseo de ser actores, de construir su propia vida de manera autónoma, pese a los obstáculos sociales que su propia experiencia cotidiana debe enfrentar. 
A continuación, mostraremos los principales resultados, interpretados desde la sociología de la acción, anteriormente reseñada.

Frente a la pregunta planteada en los distintos grupos de discusión en torno al mal juicio ciudadano sobre las políticas sociales destinadas a la superación de la pobreza, la primera respuesta, sobre todo en los grupos compuestos por adultos y ancianos es un cuestionamiento a la prenoción de "pobreza" que la pregunta moviliza:

¿A qué se refiere?, ¿netamente a la cantidad de ingreso que tiene?, ¿cuánto come o no come en el dia? ¿qué? Por ejemplo, a una persona, yo tengo ingreso pero, yo digo, mis gustos en la casa, pero si yo quiero ir a la ópera no puedo, o sea, ¡ese nivel de pobreza también?, ¿o no?, ¿eso es pobreza? O sea, yo digo para comer y para, para pagar el colegio supongamos, mis hijos, no tengo hijos, pero pago las necesidades básicas ¿ah? Pero si yo quiero ir al Caribe, por ejemplo, ¿puedo hacerlo?

Esta afirmación nos muestra una ambigüedad que se reiterará a lo largo de la discusión. Los pobladores no se identifican con la definición de pobreza que pareciera tener el Estado (“¿cuánto come o no come en el día?”), sino más bien con deseos insatisfechos ("si yo quiero ir a la ópera, no puedo”).

Esta distancia establecida en relación a la definición de pobreza lleva a dos respuestas ambiguas: por un lado, ellos asocian estrechamente la pobreza con una cierta degradación de las personas. Un poblador declara:

Yo pienso que la gente confunde mucho la pobreza con lo que es la cochiná y la suciedad, porque hay gente que es muy pobre, tiene a lo mejor sus cosas básicas pero si uno entra a esa casa la hediondez, el mosquerio, cosas sin hacer, loza por allá, el montonerio por uno y por otro lado.

Sin embargo, por otro lado, en muchos discursos se puede apreciar el carácter inclusivo de esta dimensión, por ejemplo:

Pobreza se define también por una parte, a mi, que en su vida también han tenido, han trabajado, y ha llegado un momento en que en este momento la situación económica cae dificil para todos. 
Para ellos, las estrategias de lucha contra la pobreza desarrolladas por el Estado intentan combatir el primer sentido asignado al término:

... ahi la inversión que es para ver, que tiene el gobierno, como tú dices ahi, ¿dónde está? Es para la gente que está en una parte que es el acabose, que ya está en el barro, las camas sin hechas, no les gusta la limpieza, no ve una parte donde que la persona necesita, la que ha podido subsistir a base de esfuerzo.

La crítica se apoya, así, en la valorización del esfuerzo personal para hacer frente a los obstáculos sociales. La pobreza es un elemento que determina su condición social, pero su subjetividad se constituye ahí donde se revela incapaz de negar sus deseos. La subjetividad popular puede entenderse como una lucha contra los obstáculos que la pobreza implica para la realización de sus deseos de ser actor.

Los pobres asistidos por el Estado, objeto de la focalización de las políticas públicas, son vistos por los entrevistados como personas que no merecen la ayuda social, ya que no quieren salir de la pobreza y reproducen dicha pasividad en su vida cotidiana, visible en la imagen de la "suciedad".

Una mujer adulta utiliza la expresión "pobreza de espíritu" para diferenciar su pobreza material, los obstáculos objetivos que implica, de la pobreza que afecta a los "otros pobres".

Yo tengo harta visión de lo que es pobreza, igual siguiendo en el mismo tema que estaban de lo material pa' mi el pobre es el pobre de espiritu, y de ahi duele más (...) yo pienso que el espiritu es el que tiene que enriquecerse, el que es pobre de espiritu nunca va a ser nada en la vida.

Por otro lado, la pobreza aparece en los discursos asociados a otros elementos: el fracaso social, la frustración, la tristeza.

Hay gente a la cual la tienen en la miseria más grande; no me lo quita nadie de la cabeza, porque hay gente, la gente está llorando, vive en un rancho, humilde.

Este sentimiento se torna dramático en los pobladores más ancianos, quienes ligan estrechamente el fracaso y la pobreza a la enfermedad y la muerte. Un poblador afirma: 
Hay gente que muere de cáncer y la gente que muere de cáncer $o$ de otras enfermedades, ancianos, jóvenes, mueren y lo único que hay es el cajón que le puede dar la municipalidad, pero no tiene ni una pastilla, ni para el dolor ni para esto, menos para entretener siquiera la vista, porque usted sabe que un condenado a muerte tiene deseo de algo, de servirse un agua, jugo o algo, hay que despedirse de esta vida de alguna manera, ni eso, ni para eso tienen.

Es destacable la importancia que se le da a la ayuda social para la construcción de su imagen de la pobreza. Las personas más pobres solo reciben de la municipalidad un ataúd. Al mismo tiempo, aparece nuevamente la afirmación del deseo como elemento decisivo en la subjetividad. Incluso un condenado a muerte tiene deseo de algo.

El abandono social que la pobreza pareciera traer surge como un acontecimiento producido más allá del individuo, fuera de su voluntad. La pobreza es un obstáculo externo que parece impedir la realización del deseo que la subjetividad comporta.

La pobreza implica una ruptura con el vínculo social; al contrario, los pobladores demandan integrarse de forma activa en la producción de la sociedad:

Nosotros queremos dignidad como seres humanos, como personas, porque nosotros no pedimos, porque necesitan de la gente de trabajo, necesitan de las poblaciones donde estoy.

Un jubilado agrega:

Lo que tenemos que pedir es que nos den trabajo porque todavía valemos, todavía somos seres humanos, todavía podemos darle algo a la sociedad, que no nos arrinconen como seres humanos y no nos marginen como personas. Valemos nosotros, tenemos valores muy grandes, porque hemos trabajado en nuestra vida por la sociedad. Hemos trabajado en tantas cosas no solo para nosotros; entonces por qué ahora nos hacen a un lado como cosas inservibles entonces. 
En esta cita los obstáculos de la pobreza se asocian con aquellos impuestos por la vejez. En ambos casos la persona quiere actuar, no quiere recibir dinero, sino trabajo. La acción que comporta el trabajo le permite definir su condición de ser humano.

Esta reivindicación de la "condición humana", aparentemente no reconocida por la institucionalidad, es un argumento muy recurrente en los discursos interpretados. Por ello es que construimos la dimensión "reconocimiento" para englobar aquellos textos que identifican el sufrimiento con el agravio a esta condición.

Un poblador señala:

El problema que quieren evaluar nuestra pobreza en el sentido de que nosotros vamos al paternalismo. Yo creo que ninguna persona que tenga un poquito de cinco sentidos, no vamos a esperar que nos den todo sino que nosotros quisiéramos tener cómo evaluar nuestras condiciones de seres humanos.

Diversos textos muestran esta misma reivindicación sin definir claramente cuál es el contenido de esa condición humana: en algunos casos es "la dignidad", en otros "el conocimiento de su realidad" o la "madurez" para administrar sus trayectorias.

Esta vacuidad del concepto nos permite entender la tensión que hay tras la construcción de significados. El sujeto lucha por construir la sociedad a partir de sus propias acciones; esta acción no tiene ningún contenido fijo, sino que representa el camino hacia el reconocimiento como un ser humano, más allá de las exigencias y de las evaluaciones sociales o políticas.

El deseo de ser reconocido como un ser humano toma el centro de la acción autónoma de los pobladores, es decir, la posibilidad de articular su propia vida es realmente la única dimensión donde aparece la expresión del "yo”. En las otras dimensiones, es a través de la degradación moral y el abandono social producidos por la pobreza que los sujetos construyen una imagen del otro. 
A partir de la sociología del sujeto de Alain Touraine se puede explicar este fenómeno. El paternalismo, contra el cual los individuos luchan para afirmar su subjetividad, es la imagen del "yo social", es decir, el conjunto de significaciones que la sociedad le impone al individuo. Son los roles con los cuales los "poderes impersonales" (Touraine, 1998) interpelan a los individuos, principalmente bajo la categoría de "pobre". Al contrario, "el sujeto no se da directamente, no aparece más que en el desgarramiento o en el exceso, cuando el actor no es reductible ni a sus roles ni a sus intereses" (Dubet \& Wieviorka, 1995, p.9).

Se ve la afirmación del individuo como sujeto presente ahí donde él lucha por constituirse en un "yo" ( $j e$ ") que enfrenta a los poderes impersonales, específicamente a la política institucional. La presencia del "yo" ( "je”) en el discurso popular es evidente cuando se habla de la necesidad de ser comprendido como un ser humano, con una capacidad de acción autónoma para articular su propia experiencia. El sujeto "poblador" deviene visible cuando el "yo social" ("moi”) se fragmenta y es incapaz de interpelar al individuo.

De esta manera, es claro que el deseo de ser actor es un elemento central para definir la subjetividad popular en la medida que construye su propia imagen. El contenido del sujeto hacia el cual los individuos orientan sus acciones no puede ser definido a priori, lo que implica una inscripción del sujeto en el devenir mismo de la historia y sus procesos sociales. Eso no significa que los procesos de subjetivación no tengan ningún contenido, sino que son definidos a partir de las luchas que los actores tienen por afirmar su subjetividad.

El deseo es un elemento político porque pone en cuestión las formas de producción y de reproducción de los valores en la sociedad. El orden social se revela como una construcción contingente sobre la producción de diferencias, dado que es incapaz de estabilizar el deseo que expresan los sujetos de construir su propia realidad. La sociedad misma deviene el objeto de deseo y de relaciones conflictuales entre los sujetos, en la medida que desean apropiarse de las orientaciones culturales hegemónicas (Laclau \& Mouffe, 1987). 
El problema del adversario social y el déficit de articulación de la subjetividad popular

En la sociología de Touraine (1992), los procesos de subjetivación, inscritos en esta lógica hegemónica, implican el reconocimiento de un adversario social. Los movimientos sociales son aquellos capaces de identificar, detrás de la producción social (simbólica y material) dicho adversario. Si bien es imposible aunar las distintas expresiones críticas en la sola noción de movimiento social, no es incorrecto teóricamente plantear dicha interrogante en el caso en cuestión.

Como muestra François Dubet: "La sociología de la acción no es una sociología de los movimientos sociales, es una sociología general que se esfuerza por analizar las conductas y las relaciones sociales en términos de movimientos sociales, buscando poner al desnudo las relaciones sociales y las orientaciones culturales que construyen las prácticas sociales" (p.28).

En los discursos analizados es posible constatar dos niveles distintos en donde las personas entrevistadas sitúan al adversario social, a saber: 1) el nivel estructural y 2) el nivel de la política institucional.

El primer nivel de análisis identifica a los empresarios. Se ubica este discurso a un nivel estructural, dado que reproduce, en gran medida, la contradicción capital/trabajo, situada al centro de la producción social por el pensamiento marxista. El recurso a la explotación económica es central en este nivel. Un poblador moviliza este argumento:

No tenimos, no tenimos esa conciencia, pero el que nos llama a la pobreza, el que nos llama a la pobreza a nosotros es el capitalismo, el capital nos deja sin pega, ;hacen lo que quieren! Yo le digo una cosa: jse burlan de los Estados! porque la plata es la que manda.

En este nivel, los distintos elementos que utilizan se corresponden al planteamiento clásico marxista: la centralidad de la contradicción capital/trabajo como determinante estructural del capitalismo, la debilidad del Estado frente a esta contradicción y el poder de la ganancia para definir los parámetros de desarrollo de una sociedad. 
En esta misma dirección, otra persona agrega:

¿Quién, quién, quién nos tiene metidos hasta ahora en la pobreza?: los empresarios pos m'ija, si aqui no tenemos pa' qué.

En relación al segundo nivel, aquél de la política institucional, el Estado está en el centro de las críticas planteadas: el Estado sigue siendo a mi juicio el generador de la pobreza. Sin embargo, en sus discursos, no existe una continuidad entre la dimensión estructural y la dimensión política. Así, el Estado no expresa los intereses de una clase, sino más bien de las personas específicas que están en el poder.

Un joven entrevistado destaca el interés electoral que está detrás de la preocupación por la pobreza:

Al final que uno se da cuenta que al gobierno le conviene tener a la gente pobre po', porque a través de ellos va a conseguir su voto, porque siempre van a ser su bandera de lucha, va a ser jah, yo voy en la superación de la pobreza, yo por el pueblo!, Y el pueblo no sépo'. Igual de repente todavía habemos gente ignorante que todavia le creemos.

El Estado aparece como la expresión de intereses individuales y estratégicos con el objetivo de perpetuarse en el poder. La política misma asume este carácter, perdiendo relación con la producción hegemónica del orden social.

Dadas estas ambigüedades que se reiteran a lo largo de los grupos, se puede ver que la crítica social que construyen no es capaz de identificar un adversario social tras los procesos de modernización. En el discurso "estructuralista", los pobladores construyen un adversario en la figura del empresario; sin embargo, es difícil establecer una coherencia con la diversidad de planteamientos analizados.

La política aparece más bien como un modo de gestión de la inversión. El Estado parece ser el principal responsable de la pobreza, dado que las estrategias de lucha por la superación de la pobreza son ineficaces en la asignación de los recursos.

La importancia de recuperar esta concepción de la política es que sirve para comprender que los sujetos construyen una imagen de la política 
institucional que, según sus discursos, no considera sus propios deseos e intereses, ya sean sociales o culturales.

Los entrevistados no articulan una relación de poder con las autoridades políticas, característica central de los movimientos sociales en relación a la constitución de un adversario social. Difícilmente se puede decir que el Estado o el gobierno pueden ser concebidos como un adversario social.

La desigualdad y la pobreza, al contrario, parecen determinaciones naturales de la vida social. Al respecto, es ilustrativo el discurso de una joven:

Hay muchos que tienen much a plata y otros que tienen muy poco, muy poca plata y poco acceso a un montón de cosas que deberian ser.. que son básicos, entonces no está bien enfocada la realidad.

Hasta aquí hemos intentado mostrar el proceso de interpretación que se llevó a cabo sobre los discursos. A continuación, insertando estos discursos en prácticas sociales más amplias, se mostrarán las principales reflexiones que buscan explicar la relación entre las prácticas discursivas en torno a las dimensiones de la pobreza y el reconocimiento.

Los procesos de individualización y la política. Esbozos de una conclusión

El problema inicialmente planteado en torno al déficit de participación política, sobre todo entre los jóvenes y los sectores más pobres de la población, se torna más complejo cuando se interroga sobre la subjetividad popular. El problema se desplaza desde la relación entre la sociedad (totalidad suturada) y la política institucional, hacia la discusión sobre la relación entre lo social y lo político (Baño, 1985). En el presente artículo, se intentó mostrar cómo lo social es desde ya una producción política, en la medida que el conjunto de aspiraciones y deseos que movilizan a las personas están determinados por un distanciamiento crítico de las funciones que el orden social les atribuye.

La relación entre este registro político de la subjetividad popular y la política institucional abre nuevas preguntas en torno a la comprensión del 
carácter atomizado de la subjetividad y la debilidad organizacional fácilmente apreciable, que no pasan simplemente por una desconfianza hacia el sistema sino realmente por una transformación de la subjetividad, donde los procesos de modernización inaugurados por la dictadura han jugado un rol central.

En los distintos discursos analizados, la distancia generacional de la cual hablan los estudios se torna muy patente en torno a un proceso en particular: la individualización que acompaña la subjetivación de los más jóvenes. Éste es un factor relevante para la comprensión del comportamiento político actual (apatía), incluso electoral (derechización), de los más pobres. No pretende ser el único factor explicativo, sino que es una dimensión importante que parece necesaria considerar a la hora de realizar un análisis de la política actual.

En los sectores más jóvenes de la población (representado por dos grupos de discusión en la investigación), la expresión del deseo de ser actor es fuertemente individual. Su relación con la historia misma es particular. Si la población en la cual habitan es el resultado de una lucha colectiva, esa lucha les pertenece a sus padres o abuelos. La continuidad o discontinuidad con esta experiencia de resistencia es así una elección principalmente individual.

La individualización de sus trayectorias sociales se expresa en una crítica hacia las orientaciones tradicionales de la comunidad. Estos jóvenes aparecen menos definidos por su pasado, que por el futuro que eventualmente pudieran llegar a protagonizar. Así, la pobreza, si bien les afecta duramente, es vista como algo que es preciso superar en el corto plazo, más que un rasgo identitario.

El pasado del Chile reciente les parece un espacio de división social y conflicto que les impide reconocerse en las transformaciones actuales. Los procesos de modernización neoliberal no aparecen para los jóvenes, al contrario de los entrevistados más ancianos, como una realidad que les es impuesta. El crecimiento económico y la ideología que se ha construido en torno al éxito individual les parece una alternativa atractiva, pese a que no les impacte directamente. La política, sin embargo, no les parece ser una dimensión donde puedan superar su condición de exclusión. 
La individualización de sus procesos de subjetivación parece conformar una respuesta para autonomizar el presente de los obstáculos del pasado. Si la "población" es un espacio territorial donde la gente comparte una condición social precaria, heredada del pasado, es el individuo aislado quien debe buscar los caminos para alcanzar sus propios objetivos. La política institucional, en ese sentido, no les ofrece una alternativa, más allá del magro derecho de votar.

De hecho, los jóvenes aprecian mucho la autonomía de sus organizaciones en relación a la política del Estado. Los jóvenes, organizados en torno a sus necesidades individuales se sienten capaces de articular sus propias experiencias. La inscripción de sus organizaciones en una institución política formal, ya sea el Estado, la Municipalidad o los partidos políticos, es interpretada como una forma de subordinación de las expectativas individuales a las necesidades del colectivo, determinadas desde fuera por los intereses de la clase política.

Si se consideran las diferencias existentes entre los distintos procesos de subjetivación, se puede comprender por qué la articulación entre lo social y lo político es un fenómeno más complejo que un diagnóstico de la apatía política, en la medida que no hay elementos suficientes para determinar las formas que debe asumir la desigualdad o la pobreza para que éstas conduzcan a procesos anómicos, respuestas individuales o a la formación de una voluntad política colectiva.

Comprendiendo estas transformaciones en la subjetividad popular es que se puede entender la experiencia que los pobladores tienen de la política, la heterogeneidad que la caracteriza y la dificultad de articularse bajo una alternativa histórica, clave de la construcción contra-hegemónica de un discurso y comportamiento colectivo. 


\section{Referencias}

Adorno, T. \& Horkheimer, M. (2004) Dialéctica de la Ilustración. Madrid: Trotta.

Aranda, C. \& Cuevas, J. (2008). Tercera persona plural: la juventud invisible. Observatorio de juventud, 18, 53-63.

Baño, R (1985). Lo social y lo político. Un dilema clave del movimiento popular. Santiago: FLACSO.

Baño, R. (1995) El nuevo carácter del apoliticismo. Serie Estudios Políticos, 33, 5-28.

Baño, R. \& Faletto, E. (1992). El apoliticismo. El factor generacional. Documento de Trabajo. Serie Estudios Políticos, 25, 1-69.

Campero, G. \& Cortázar, R. (1987). Actores sociales y la transición a la democracia en Chile. Colección de estudios CIEPLAN, 25, 115-158.

Castel, R. (2009). La montée des incertitudes. París: éditions du Seuil.

De Singly, F. (2008). Le processus d'individualisation: une étape, l'entrée dans l'adolescence, in Identités de l'individu contemporain. París: Éditions Textuel.

Faletto, E. (1994). La función del Estado en América Latina. Revista Foro, 23, 5-16.

Figueroa, R. (2002). Desempleo y precariedad en América Latina. Santiago: Predes.

Foucault, M. (2007). Surveiller et punir. París: Gallimard.

Garretón, M. A. (2000) La sociedad en que vivi(re)mos. Santiago: Ediciones LOM.

González, R., Manzi, J., Cortés, F., Torres, D., De Tezanos, P., Aldunate, N., et al. (2005). Identidad y actitudes políticas en jóvenes universitarios: el desencanto de los que no se identifican políticamente. Revista de Ciencia Politica, 2, 65-90.

Honneth, A. (2008). La société du mépris. Vers une nouvelle théorie critique. París: La Découverte/ Poche.

Hopenhayn, M. (1997). Después del nihilismo. De Nietzsche a Foucault. Santiago: Editorial Andrés Bello.

Laclau, E. \& Mouffe, C. (1987). Hegemonía y estrategia socialista. Hacia una radicalización de la democracia. España: Siglo XXI editores.

Lechner, N. (2002). Las sombras del mañana. La dimensión subjetiva de la politica. Santiago: Ediciones LOM.

Madrid, S. (2005). ¿Políticos de ayer, apáticos de hoy? Generaciones, juventud y política en Chile, en C. Fuentes y A. Villar, (Eds.), Voto ciudadano. Debate sobre la inscripción electoral. Santiago: (pp. 45-84). FLACSO. 
Merklen, D. (2009) Quartiers populaires, quartiers politiques. Paris: La Dispute.

Ministerio de Planificación y Cooperación. (2003) El juicio ciudadano a las politicas sociales. Santiago: MIDEPLAN.

Paugam, S. (2002). La disqualification sociale. París: éditions PUF.

Programa de las Naciones Unidas para el Desarrollo. Santiago. (1998). Informe de Desarrollo Humano. Las paradojas de la modernización.

Rancière, J. (2006). Política, policía, democracia. Santiago: Ediciones LOM.

Ruz, L. (2008). Los jóvenes y su mirada crítica a la democracia en tiempos de cambio. Observatorio de juventud, 18, 13-20.

Toro, S. (2005). De lo épico a lo cotidiano: Jóvenes y generaciones políticas en Chile. Revista de Ciencia Política, 3, 143-160.

Touraine, A. (1992). Critique de la modernité. París: Fayard.

Touraine, A. \& Khosrokhavar, F. (2000). La recherche de soi. Dialogue sur le Sujet. París: Fayard.

Wieviorka, M. (1995). Plaidoyer par un concept. En F. Dubet \& M. Wieviorka. (Eds.), Penser le sujet. Autour d'Alain Touraine. (pp.209220). París: Fayard.

Wieviorka, M. (2008). L'intégration: un concept en difficulté. Cahiers internationaux de sociologie, 125, 221-240.

Wieviorka, M. (2008). Neuf leçons de sociologie. París: éditions Robert Laffont.

Fecha de recepción: 13 de mayo de 2010.

Fecha de aceptación: 9 de noviembre de 2010. 